\title{
EFICÁCIA DOS DIREITOS FUNDAMENTAIS E TRABALHO DIGNO NAS FEIRAS MÓVEIS
}

\author{
A. B. Cardoso' ${ }^{1}$; D. E. Ferreira ${ }^{2}$ \& G. H. Viana Júnior ${ }^{3}$ \\ ${ }^{1}$ Bolsista e graduando pela Universidade Federal do Ceará (UFC). E-mail: bolsista @ gmail.com; ${ }^{2}$ Bolsista e graduando pela Universidade \\ Federal do Ceará (UFC). E-mail: bolsista@gmail.com ${ }^{3}$; Coordenador de ação extensionista de mesmo nome do artigo. E-mail: \\ professor@gmail.com
}

Artigo submetido em Setembro/2017 e aceito em Novembro/2017

\section{RESUMO}

Diante da importância das feiras móveis como alternativa de consumo e renda para muitos indivíduos, são necessários estudos acerca da sua realidade trabalhista e práticas empreendedoras. Objetiva-se compreender a visão nativa dos feirantes em relação a aplicabilidade prática dos direitos fundamentais e do fenômeno da informalidade na feira móvel dos bairros Cidade 2000 e Praia do Futuro em Fortaleza. Utiliza-se como metodologia a pesquisa bibliográfica sobre os direitos fundamentais relacionados ao trabalho e a investigação etnográfica.
Conclui-se que a maioria dos trabalhadores relatou não ter informações suficientes das etapas de formalização. De um modo geral, não há otimismo sobre as propostas públicas e a efetivação dos direitos fundamentais, pois, segundo os feirantes, o Estado não cria políticas que favoreçam o trabalho digno. Procurou-se, esclarecê-los sobre seus direitos e as possibilidades de formalização, além de revelar a importância das feiras como oportunidade de trabalho e desenvolvimento econômico.

PALAVRAS-CHAVE: Direitos fundamentais; Trabalho Digno; Feiras Móveis; Informalidade; Etnográfia

\section{EFFECTIVENESS OF FUNDAMENTAL RIGHTS AND DECENT WOR AT MOBILE FAIRS}

\begin{abstract}
Given the importance of mobile fairs as an alternative of consumption and income for many individuals, studies are necessary on their labor reality and entrepreneurial practices. It aims to understand the native view of the stallholders in relation to the practical applicability of fundamental rights and the phenomenon of informality in the mobile fair of the Cidade 2000 and Praia do Futuro neighborhoods in Fortaleza. It was used as methodology the literature about fundamental rights related to labor and an ethnographic research. Most of the workers reported
\end{abstract}

\begin{abstract}
not having enough information of the formalization steps. Generally speaking, there is no optimism about public proposals and the realization of fundamental rights, because, according to the stallholders, the state does not create policies that favor decent work. It was sought, clarify them about their rights and the possibilities of formalization, besides revealing the importance of the fairs as an opportunity of work and economic development.
\end{abstract}

KEYWORDS: Fundamental Rights; Decent Work; Mobile Fairs; Informality; Ethnography. 


\section{INTRODUÇÃO}

O final do século XX foi marcado por mudanças profundas na estrutura de produção e no contexto mercadológico. A partir da evolução tecnológica e científica, com a concorrência global acirrada e o advento do capitalismo financeiro, muitos trabalhadores necessitaram optar pelo trabalho informal (ausência de benefícios legais) em vez do trabalho formal (maior capacitação, direitos trabalhistas), a fim de assegurar sua subsistência. Tal contexto foi marcado por relações trabalhistas menos estáveis, diversificação das formas de trabalho e, em muitos casos, pela não garantia de direitos mínimos existenciais para a promoção do trabalho digno, proporcionando um nível de precarização das relações laborais (SINGER, 2013, p. 181).

No Brasil, esse cenário influenciou a expansão da informalidade, pois os indivíduos encontraram-se distantes das ofertas de empregos formais e optaram por manter o sustento básico através de atividades organizadas em pequena escala de produção e, em sua maioria, não regulamentadas pelo Estado. A cultura da informalidade possui, ainda, os seguintes atributos: propriedade familiar do empreendimento, origem e aporte próprio dos recursos, facilidade de ingresso, uso intensivo do fator trabalho e aquisição das qualificações profissionais à parte do sistema escolar de ensino, não regulação do Estado (OIT, 1972).

Nesse contexto, as feiras móveis (que ocorrem em bairros diferentes a cada dia da semana) apresentam-se como um dos exemplos de comércio de rua característico dos espaços urbanos da atualidade. Segundo Mafra (2007, p. 191), a questão do comércio de rua relacionase com o problema do desemprego, do uso do espaço urbano e do crescimento das atividades econômicas informais, tornando-se um fenômeno proeminente nas cidades brasileiras. Nesse quadro estão inseridos os feirantes, os ambulantes, os artesãos e os camelôs, que, em muitos casos se encontram à parte do mercado formal.

Mesmo com uma estrutura laboral desigual e competitiva nos mercados modernos, as feiras móveis passaram a representar um símbolo de resistência às pressões do capital. Logo, são importantes estudos acerca do potencial empreendedor nesses comércios e da sua realidade trabalhista no que concerne às formas de apropriação, pelos feirantes, dos Direitos Fundamentais previstos na Constituição da República Federativa do Brasil de 1988, tais 
como: igualdade, liberdade laboral, saúde, segurança, propriedade, meio ambiente, dentre outros.

Assim, a compreensão da situação trabalhista vivenciada pelos feirantes possibilita a desconstrução de perspectivas que mensuram o setor informal apenas como "categoria de empregado sem carteira assinada, ou de atividades econômicas selecionadas a priori, ou de empresas que operam com um número pequeno de empregados, ou de trabalhadores que auferem baixos rendimentos" (CACCIAMALI, 2000 p. 155), algo que será explorado ao longo do texto. Além disso, torna-se viável investigar o nível de eficácia dos direitos fundamentais para garantir um trabalho digno e inclusão produtiva e social a esses empreendedores.

Perante a conjuntura apresentada, a pesquisa possui o objetivo geral de compreender a visão nativa dos feirantes acerca da aplicabilidade prática dos direitos fundamentais e do fenômeno da informalidade na feira móvel dos bairros Cidade 2000 e Praia do Futuro em Fortaleza. Logo, têm-se as seguintes questões: Quais as formas de apropriação dos Direitos Fundamentais pelos feirantes e em que medida há a adequada efetivação destes na feira móvel pesquisada? Qual a visão dos feirantes sobre a importância da aplicabilidade desses direitos?

O presente artigo faz parte do projeto de extensão "Feiras Móveis em Fortaleza: microempreendedor individual e o fenômeno da informalidade no comércio de rua" e possui caráter transdisciplinar, pois se baseia em conteúdos jurídicos (transmitir saberes dos vários ramos do Direito), contábeis (etapas da formalização, cumprimento das obrigações trabalhistas e tributárias) e antropológicos (compreender a visão nativa sobre os direitos fundamentais). Como objetivos específicos têm-se: a) disseminar os conhecimentos jurídicos constitucionais, trabalhistas, previdenciários e contábeis que desenvolvam o trabalho nas feiras; b) Influenciar a efetivação dos direitos fundamentais pela criação de políticas de inclusão social, saúde e bem-estar desse grupo, além de aproximação da sociedade com a realidade desses trabalhadores.

Utiliza-se como metodologia a pesquisa bibliográfica sobre os direitos fundamentais relacionados ao trabalho e a investigação etnográfica - "delinear as leis e os padrões de todos os fenômenos culturais, isolando-os de fatos irrelevantes" (MALINOWSKI, 1922, p. 24) - da visão nativa dos feirantes acerca dos seus direitos e a eficiência destes nos setores informais 
da economia. Para tal, foram realizadas visitas semanais na feira pesquisada, por meio da descrição densa dos fenômenos observados em campo.

\section{TRABALHO: PERSPECTIVAS SOCIOLÓGICAS E JURÍDICAS}

O trabalho refere-se a "realização de tarefas que envolvem o dispêndio de esforço mental e físico, com o objetivo de produzir bens e serviços para satisfazer necessidades humanas" (GIDNESS, 2001, p. 378). É por meio da força laboral que o homem obtém recursos que serão utilizados para a manutenção das condições mínimas de dignidade humana. Além disso, tal prática é crucial para a análise social, pois auxilia a interpretar o funcionamento da sociedade, incluindo suas relações pessoais e de produção (MARTINS, 2017, p. 39).

Verifica-se o papel dinâmico desse mecanismo produtivo na construção social e econômica das sociedades, pois ele impulsiona a produção e a acumulação de capital nacional por meio do desenvolvimento de diversas atividades e possibilita maior interação do homem com a natureza. Desse modo, as atividades laborais possuem relevância na história produtiva da humanidade, as quais se apresentam de maneira diversificada e complexa no contexto social.

As intensas transformações no trabalho referem-se à transição da economia industrial para a economia de serviços. Observou-se uma pluralidade de atividades desempenhadas nos mercados, porém nem todas se encontravam abrangidas pela legislação vigente, acarretando no alargamento da Economia Informal, a qual se refere a "transações fora da esfera do emprego regular, que implicam, por vezes, a troca de dinheiro por serviços prestados, mas que também implicam frequentemente a troca direta de bens ou serviços” (GIDNESS, 2001, p. $378)$.

Diante da importância socioeconômica do trabalho, seja ele formal ou informal, tornaram-se necessários dispositivos que buscassem promover o progresso sustentável da sociedade no âmbito laboral e condições que favorecessem o trabalho digno aos indivíduos. Nessa perspectiva, após constantes mudanças no decorrer da história trabalhista brasileira, foi promulgada a Constituição da República Federativa do Brasil de 1988, passando a ser 
considerada a constituição cidadã e a versar em seu título II sobre os direitos e garantias fundamentais, declarando diversos direitos aos trabalhadores e valorizando o trabalho humano e a solidariedade (MARTINS, 2017, p.162).

Entretanto, vale ressaltar que a democracia política não resolveu as dificuldades econômicas mais graves como a desigualdade e o desemprego. Continuam os problemas sociais, principalmente na educação, saúde e saneamento. Mas as maiores problemáticas na área social estão relacionadas com a persistência das desigualdades que marcam o país desde a independência (CARVALHO, 2008, p. 199-207).

Assim, com a aprovação da referida Constituição, outros direitos também se incorporaram ao âmbito trabalhista, tais como: liberdade laboral, direito a uma propriedade, saúde, segurança, meio ambiente equilibrado, dentre outros. Tais direitos serão analisados como prerrogativas que possibilitam a implementação do trabalho digno no Brasil.

\subsection{DIREITOS HUMANOS E FUNDAMENTAIS NO ORDENAMENTO JURÍDICO}

Antes de discorrer acerca dos Direitos Fundamentais previstos na Constituição Federal de 1988 do Brasil, é importante evidenciar a distinção entre os direitos humanos e direitos fundamentais. $\mathrm{O}$ primeiro refere-se aos princípios que estabelecem aspectos de dignidade, igualdade e liberdade a todos os seres humanos, já o segundo é entendido como a positivação dos direitos no âmbito de cada Estado, de acordo com um ordenamento jurídico específico (CAVALCANTE, 2007, p. 15).

Nesse contexto, tem-se que os direitos do homem são direitos históricos, os quais emergem das lutas que este trava pela busca da sua própria emancipação e das transformações das suas condições de vida. Assim, a Declaração Universal dos Direitos do Homem de 1948 introduz, pela primeira vez na história, um sistema de valores universal de fato, pois o consenso sobre sua validade e sua capacidade para reger os destinos da comunidade futura dos homens foi declarado de forma explícita (BOBBIO, 1992, p. 32-33).

Corroborando com a mencionada Declaração, a qual o Brasil é signatário, a Constituição Federal de 1988 favorece a prática do trabalho digno ao oficializar os direitos fundamentais dos cidadãos, tais como: liberdade laboral (art. $5^{\circ}, \mathrm{XIII}$ ), direitos sociais (art. $6^{\circ}$ - saúde, trabalho, segurança, previdência), propriedade (art. $5^{\circ}$, XXII e XXIII), meio ambiente 
equilibrado (art. $170^{\circ}, \mathrm{VI}$ ), dentre outros. Para a garantia do Estado Democrático de Direito, tais direitos, como enunciado no Art. $1^{\circ}$ da $\mathrm{CF} / 88$, devem basear-se no pleno exercício dos fundamentos da dignidade da pessoa humana e da valorização social do trabalho.

De acordo com Barroso (2003, p. 37) "o principio constitucional da dignidade da pessoa humana identifica um espaço de integridade moral a ser assegurado a todas as pessoas por sua só existência no mundo". Observam-se os aspectos valorativos inerentes ao princípio da dignidade humana, os quais se mantêm em constante expansão e na busca pela proteção dos indivíduos, inclusive no âmbito trabalhista. Tal princípio é, atualmente, a mais forte expressão de constitucionalização dos direitos humanos (CAVALCANTE, 2007, p. 28).

Torna-se importante a compreensão acerca do nível de eficácia e aplicabilidade das normas constitucionais já elencadas no presente estudo. Em suma, a eficácia dos atos jurídicos refere-se ao seu papel para a geração de efeitos, atingindo a finalidade para a qual foi criado. Utiliza-se na investigação a seguinte classificação acerca da eficácia normativa: a) eficácia plena e aplicabilidade imediata (independem de providência normativa posterior à sua aplicação, possuindo normatividade suficiente); b) eficácia contida e aplicabilidade imediata (passíveis de restrições por atos normativos, como as leis); eficácia limitada ou programática (sem normatividade suficiente e dependem da integração infraconstitucional para exercerem seus efeitos de forma ampla, orientam os programas estatais) (BARROSO, 2003, p. 91-92).

Considera-se como uma inovação da $\mathrm{CF} / 88$ o fato dos direitos fundamentais constituírem valores superiores de toda a ordem constitucional e jurídica. Além disso, deve-se destacar que, segundo o art. $5^{\circ}, \S 1^{\circ} \mathrm{da} \mathrm{CF} / 88$, as normas definidoras de tais direitos possuem aplicabilidade imediata. Fica, então, consagrado o status jurídico diferenciado e reforçado de tais direitos na constituição brasileira (SARLET, 2009, p. 66).

Cumpre salientar que os direitos fundamentais são classificados pela doutrina, de um modo geral, de acordo com três gerações ou dimensões, quais sejam: os de primeira geração, tendo como titular os indivíduos (direito à liberdade laboral, à propriedade); os de segunda geração, baseados na igualdade, os chamados direitos sociais, culturais e econômico (trabalho, saúde, segurança); os de terceira geração, ligados à solidariedade (desenvolvimento, meio ambiente, qualidade de vida). Nesse aspecto, o próximo tópico busca analisar em que medida os direitos ora elencados possuem uma inter-relação com o trabalho. 


\subsubsection{DIREITOS FUNDAMENTAIS NO ÂMBITO TRABALHISTA}

Em cada direito fundamental previsto na Constituição Federal de 1988 se faz presente um aspecto ou, pelo menos, alguma projeção da dignidade da pessoa, sustentando a ideia de que tais prerrogativas estão intimamente ligadas com necessidade de estabelecer condições mínimas existenciais para os seres humanos (SARLET, 2007, p. 86-87). Nesse contexto, serão abordados alguns dos direitos fundamentais que se relacionam de maneira imprescindível na promoção do desenvolvimento social e sustentável do trabalho no Brasil.

Dentre os direitos de primeira geração já enunciados tem-se no art. $5^{\circ} \mathrm{XIII}$ da $\mathrm{CF} / 88$ que "é livre o exercício de qualquer trabalho, ofício ou profissão, atendidas as qualificações profissionais que a lei estabelecer". Tal dispositivo reflete a questão da liberdade laboral demonstrando que o trabalho deve ser exercido de acordo com as escolhas individuais dos cidadãos, desde que respeitados os requisitos estabelecidos na legislação vigente. Ademais, no art. $5^{\circ}$ XXII, é "garantido o direito à propriedade", o qual se aplica ao trabalho a partir do momento que a falta de um espaço adequado para o desempenho de determinada atividade profissional compromete o exercício pleno de uma vida com o mínimo de dignidade.

Exemplificando os direitos de segunda geração têm-se no art. $6^{\circ}$ da $\mathrm{CF} / 88$ os direitos sociais, os quais possibilitam "melhores condições de vida aos mais fracos e tendem a realizar a igualização de situações sociais desiguais" (SILVA, 2014, p. 288). Embora o referido artigo englobe um rol de direitos sociais, destacam-se, no contexto estudado, os seguintes direitos: saúde, trabalho, segurança, previdência social e assistência aos desamparados. Em suma, os direitos fundamentais de liberdade e igualdade outorgados aos trabalhadores têm o intuito de assegurar-lhes uma autonomia pessoal em face dos poderes sociais, sendo o direito ao trabalho um dos principais direitos fundamentais do homem (SARLET, 2007, p. 91-94).

Ainda sobre os direitos de segunda geração, a CF/88, no art. $5^{\circ}$, caput, expressa que "todos são iguais perante a lei, sem distinção de qualquer natureza", seja por raça, sexo, origem, trabalho, idade. Isso demonstra o direito à igualdade sem distinção de sexo (art. $3^{\circ}$, IV, e art. $7^{\circ}, \mathrm{XXX}$ ), e de trabalho (art. $7^{\circ}, \mathrm{XXX}$ e XXXII). Os indivíduos devem ter tratamento igualitário nos postos de trabalho desde que demonstrem igual condição ao 
exercerem a mesma atividade, assim, "a paridade de tratamento aqui garantida diz respeito às condições de exercício de funções e de critério de admissão que têm que ser as mesmas para todos, quanto ao valor do trabalho, não se exigindo a paridade de resultado produtivo" (SILVA, 2014, p 228).

Os direitos ao desenvolvimento e ao ambiente ecologicamente equilibrado (art. $170^{\circ}$ e $225^{\circ}$ da $\mathrm{CF} / 88$ ) são de terceira geração. De acordo com o art. $11^{\circ}$ da Declaração sobre o Direito ao Desenvolvimento das Nações Unidas o direito ao desenvolvimento corresponde a "um direito inalienável de toda pessoa humana e de todos os povos, em virtude do qual estão habilitados a participar do desenvolvimento econômico, social, cultural e político, a ele contribuir e dele desfrutar, garantindo-se a plena realização dos direitos humanos" (LENZA, 2012, p. 1200). Nota-se que o tal prerrogativa está ligada com a questão ambiental, pois o espaço onde o homem se estabelece é influenciado, diretamente, pelas suas atividades, sejam elas econômicas, sociais, culturais ou políticas.

O ordenamento jurídico brasileiro, nos termos do art. 170, caput, e VI da CF/88, determina que a ordem econômica, baseada na valorização do trabalho humano e na livre iniciativa, tem como finalidade assegurar a todos existência digna, conforme os preceitos da justiça social. Para tal, deve-se observar, dentre outros princípios, o da defesa do meio ambiente, garantindo métodos diferenciados de acordo com o impacto ambiental dos bens e serviços transacionados (LENZA, 2012, p. 1201).

Em suma, como menciona Bonavides (2004, p. 278), “o Estado social no Brasil aí está para produzir as condições e os pressupostos reais e fáticos indispensáveis ao exercício dos direitos fundamentais". Pressupõe-se que é preciso garantir tais direitos para a promoção do trabalho digno nos postos laborais, inclusive nas feiras móveis. O próximo tópico irá revelar a importância das feiras como alternativa de trabalho e as possibilidades de formalização das suas relações trabalhistas, de forma a promover os direitos já mencionados.

\subsection{O TRABALHO NA FEIRA MÓVEL E O PROCESSO DE FORMALIZAÇÃO}

A feira móvel pesquisada representa um exemplo do comércio de rua típico das cidades brasileiras. Mesmo com o crescimento mercadológico e concorrência acirrada, há 
diversos aspectos que possibilitam a resistência dessa prática laboral nos espaços urbanos, tais como: fidelidade da clientela, produtos que atraem os consumidores, traços de sociabilidade, trabalho transmitido por gerações, ausência de oportunidades no mercado formal, dentre outros.

Apesar das transformações ocorridas no campo estudado (diminuição das vendas, aumento dos pontos comerciais nos arredores, conflitos por espaço), a feira manteve-se como oportunidade de consumo e fonte de renda para muitos indivíduos, haja vista o dinamismo presente nas atividades comerciais desempenhadas. Observa-se que ela constitui, além de um espaço de trocas comerciais, um retrato da multiplicidade urbana, tornando-se possível a interligação de uma complexa estrutura no que tange aos aspectos sociais e culturais de gerações, as quais encontraram nessa prática laboral recursos essenciais para sobreviverem.

Diante da relevância da feira, torna-se importante analisar a realidade das suas condições trabalhistas. Segundo pesquisa realizada em 2016 na mesma feira móvel, teve-se a quantidade de 13 (treze) feirantes, em conversa com 35 deles, registrados como $\mathrm{MEI}^{1}$ ou trabalhador autônomo, embora haja a predominância da informalidade laboral, aos poucos, a formalização está ganhando visibilidade entre os comerciantes (BRASILEIRO, CAVALCANTE, 2016, p. 55).

\section{MATERIAIS E MÉTODOS}

Inicialmente, o presente artigo pautou-se em uma pesquisa bibliográfica, a partir de técnicas de análise dos conteúdos científicos, legislativos e doutrinários. Tal pesquisa permite ao investigador a cobertura de uma gama de fenômenos acerca do tema em estudo, a fim de analisar diferentes concepções divulgadas (GIL, 2008, p. 50). Busca-se fomentar discussões sobre a temática dos direitos fundamentais relacionados diretamente com o trabalho praticado pelos feirantes, além de analisar o nível de efetivação de tais direitos na realidade pesquisada.

Posteriormente, por meio de visitas semanais à feira, realizou-se a investigação etnográfica através de uma descrição densa (GEERTZ, 1989) da visão de 47 (quarenta e sete)

\footnotetext{
${ }^{1}$ Microempreendedor Individual (MEI): é o pequeno empresário individual que atende os seguintes requisitos: a) faturamento anual de $\mathrm{R} \$ 60.000,00$ (sessenta mil reais); b) não seja sócio, administrador ou titular de outra empresa; c) tenha no máximo um empregado; d) deve exercer uma das atividades previstas no Anexo XIII da Resolução do Comitê Gestor do Simples Nacional de nº 94/2011.
} 
feirantes no que diz respeito à apropriação dos direitos fundamentais, verificando a influência da legislação no aperfeiçoamento do trabalho praticado por esses comerciantes. O campo empírico de incidência da pesquisa foi a feira móvel que percorre os bairros Cidade 2000 e Praia do Futuro em Fortaleza, pois esta representa o comércio de rua característico dos bairros mencionados e mantêm uma relação sociocultural com o crescimento mercadológico local.

Em suma, fazer etnografia consiste em tentar ler um manuscrito estranho, cheio de incoerências e comentários tendenciosos (GEERTZ, 1989, p. 20). As boas etnográficas consideram a comunicação estabelecida com o contexto da situação a qual estão inseridas, transformam o que foi vivo e intenso na pesquisa de campo para a linguagem escrita, e, por fim, detectam a eficácia social de forma analítica (PEIRANO, 2014, P. 10).

Nesse sentido, adentrando no campo de pesquisa, buscou-se captar o discurso dos feirantes acerca da formalização (se ela era vantajosa ou não), se eles tinham informações sobre as etapas de registro trabalhista (como MEI, trabalhador autônomo ou empregado), se havia o conhecimento dos seus direitos fundamentais e qual a importância destes no momento das suas reivindicações. A seguir serão transcritos depoimentos de alguns feirantes que compartilharam suas visões sobre a formalização trabalhista e os direitos fundamentais.

\subsection{OLHAR DO FEIRANTE SOBRE DIREITOS FUNDAMENTAIS E FORMALIZAÇÃO}

A partir dos diálogos traçados com 47 (quarenta e sete) feirantes, pretende-se investigar a forma como estes se apropriam dos direitos fundamentais na sua realidade trabalhista. Além disso, busca-se apreender a fala desses comerciantes sobre a formalização laboral. Dentro da amostra coletada, apenas 5 (cinco) narrativas serão descritas como expressões emblemáticas que resumem da melhor maneira tipos de visões encontradas na feira sobre a temática proposta, assim, a realidade descrita não deve ser generalizada.

A convivência semanal com os feirantes possibilitou uma maior compreensão da sua realidade trabalhista e dos obstáculos que enfrentam enquanto comerciantes de rua. Para tal, teve-se a necessidade de se desvincular de qualquer conceito preestabelecido em relação a 
esses trabalhadores, possibilitando a investigação da real visão desse grupo e, assim, analisar as suas necessidades perante o Estado e sociedade como um todo.

O primeiro depoimento a ser analisado refere-se a uma comerciante que atua no setor de frutas e verduras a menos de um mês. A primeira informante revela o fato de ter aceitado o trabalho por necessidade, ela nunca pensou em trabalhar nesse ramo, porém, as facilidades de ingresso e a não exigência de experiência permitiram que ela se juntasse a esse comércio. A feirante presta serviços para o efetivo dono da barraca e recebe como contraprestação diária cerca de $\mathrm{R} \$ 30,00$ (trinta reais). Algo que chamou atenção foi o fato dela receber um valor inferior a outro feirante do sexo masculino, o qual recebe $\mathrm{R} \$ 50,00$ (cinquenta reais), durante a mesma jornada de trabalho e desempenhando as mesmas atividades, quais sejam: ensacar mercadorias, debulhar feijões, ajudar no Caixa, dentre outras. Acerca da formalização ela demonstrou interesse em se regular como empregada, porém acredita que o seu tomador de serviços não aceitaria, devido aos encargos trabalhistas (salário, FGTS). O depoimento revela que, na realidade das feiras, muitos indivíduos não possuem o direito à igualdade salarial entre gêneros resguardado, pois é comum deparar-se com situações como esta, em que o homem ganha mais que a mulher.

O segundo informante, o qual é feirante há 25 anos, anunciou o papel da feira móvel em relação ao crescimento pessoal e profissional dos indivíduos. No caso deste trabalhador, a feira permitiu que ele iniciasse nesse ramo como ajudante, sem muitos conhecimentos acerca do mundo dos comércios. Mas foi nesse contexto em que ele obteve a oportunidade de apreender diversos conhecimentos acerca desse empreendimento e, então, conseguiu recursos para abrir o seu negócio e ser dono da sua própria barraca. Hoje, ele contrata outros ajudantes, compra as mercadorias para revenda, possui seu veículo. Algo que também foi facilitado com o seu registro como MEI, pois ele adquiriu mais créditos e financiamentos para aperfeiçoar suas atividades comerciais. Verifica-se a aplicação do direito ao desenvolvimento econômico e laboral, como preceitos que possibilitam a prática de tarefas que possuem um retorno satisfatório ao cidadão e influenciam o seu potencial empreendedor.

O terceiro informante está na feira a pouco mais de um ano e atua no setor de vestuários. No seu depoimento foi possível notar o pessimismo existente em relação às promessas de políticas que favoreçam o trabalho nas feiras móveis. Este mencionou acerca de 
um antigo compromisso da Prefeitura em instalar banheiros químicos no espaço utilizado pelos feirantes, o que facilitaria bastante o acesso mínimo às condições dignas de saúde e higiene. Outro ponto a ser abordado pelo feirante foi a ausência de cumprimento de uma ação que buscava efetivar a revitalização e padronização da feira, a fim de melhorar o espaço urbano. Entretanto, essas estruturas jamais foram colocadas em prática, aumentando a incredibilidade dos trabalhadores no Estado e em suas ações governamentais. Evidencia-se a não aplicação dos direitos ao meio ambiente e a não valorização social do trabalho.

Ao ser questionado sobre sua condição trabalhista o terceiro informante relatou que trabalha desde os 15 anos, aos 17 anos passou a ter carteira de trabalho assinada e, hoje, é MEI. Ele não considera o processo de formalização burocrático, pelo contrário, acha bem simples. Isso demonstra uma perspectiva que visualiza o MEI como uma oportunidade para quem parecia condenado às condições trabalhistas precárias de direitos da economia informal.

A quarta informante está na feira há 30 anos no setor de vestuários e destacou outro aspecto presente nesse âmbito trabalhista, é justamente a ausência de uma segurança pública no local. Segundo sua narrativa, nos dias de feira, sempre os feirantes arrecadam certa quantia e, juntos, conseguem custear um segurança particular. De acordo com a feirante, não há uma quantia mínima a ser entregue, cada um contribui com o que lhe é cabível. Mas, em média, há a colaboração com cerca de $\mathrm{R} \$ 2,00$ (dois reais) a $\mathrm{R} \$ 5,00$ (cinco reais), depende muito do lucro auferido no dia trabalhado. Dessa forma, observa-se que, mesmo sendo um direito fundamental dos cidadãos brasileiros, o déficit de segurança permanece representando uma problemática no comércio de rua e nas cidades como um todo.

No que diz respeito ao processo de formalização a quarta informante relatou que paga INSS como trabalhador autônomo, por isso não possui interesse em se formalizar como MEI. Além disso, ela não visualiza vantagens nesse registro pelo simples fato de não conhecer afundo os benefícios previdenciários, trabalhistas, creditícios e tributários desse registro. Como a visão dessa comerciante, muitos outros feirantes não identificam qualquer benefício na formalização como MEI devido à insuficiência de informações dos órgãos responsáveis.

O quinto informante revende calçados e relatou estar na feira desde criança, pois seus pais atuavam nesse ramo mesmo antes do seu nascimento. Isso demonstra os aspectos da feira transmitidos por muitas gerações. Como cresceu nesse ambiente, o feirante possui bastante 
experiência acerca dos mecanismos de vendas, tais como: controle de preços das mercadorias, estratégias para atrair clientes, valor dos fretes, organização da barraca, dentre outros. Esse comerciante demonstrou estar na feira por possuir autonomia na escolha da sua atividade laboral e também por tradição familiar. Tal narrativa apresenta a perspectiva do cidadão de ter o direito de liberdade para exercer certa profissão, onde a sociedade e o Estado possuem o papel de respeitar os motivos individuais desses trabalhadores sobre a escolha do seu labor.

\section{RESULTADOS E DISCUSSÕES}

Embora se tenha destacado 5 (cinco) narrativas, conforme os diálogos estabelecidos com os 47 (quarenta e sete) feirantes, foi possível constituir uma classificação do seu nível de conhecimento acerca dos direitos fundamentais. Além disso, traçou-se um paralelo entre a visão nativa e a aplicabilidade prática de alguns desses preceitos sob os seguintes aspectos: a) nível de igualdade laboral; b) acesso aos direitos sociais (trabalho, saúde, segurança, previdência); c) favorecimento ao desenvolvimento econômico e meio ambiente equilibrado;

A visão dos feirantes acerca dos seus direitos foi bastante heterogênea. Embora muitos não saibam o que são os direitos fundamentais positivados, todos demonstraram saber, mesmo superficialmente, que possuem sim direitos enquanto cidadãos brasileiros, como pode ser demonstrado na tabela a seguir:

Quadro 1: Nível de conhecimento dos feirantes sobre seus direitos.

\begin{tabular}{|l|c|}
\hline \multicolumn{1}{|c|}{ NÍVEL DE CONHECIMENTO DOS SEUS DIREITOS } & N \\
\hline CONHECEM SUPERFICIALMENTE & 29 \\
\hline CONHECEM POUCO & 11 \\
\hline NÃO CONHECEM & - \\
\hline NÃO QUISERAM SE PRONUNCIAR & 07 \\
\hline TOTAL & $\mathbf{4 7}$ \\
\hline
\end{tabular}

Fonte: Arquivo pessoal do autor (2017).

Muitos feirantes, apesar de conhecerem seus direitos, não sabem que estes estão previstos na Constituição brasileira e que podem ser reivindicados. Ademais, em geral, esses comerciantes expressaram não ter confiança em tais preceitos, pois, mesmo previstos constitucionalmente, muitos não são efetivados. Isso dificulta o acesso à justiça social e cidadania desses trabalhadores. 
Os depoimentos dos feirantes foram em desencontro com fatos que respeitem o princípio da igualdade entre gêneros e salarial estabelecido na $\mathrm{CF} / 88$, demonstrando que não há uma instituição que efetive mecanismos igualitários a esses trabalhadores. Foram encontradas diversas situações que afirmaram a presença de desigualdade salarial entre homens e mulheres, mesmo praticando as mesmas atividades em igual jornada de trabalho.

A insatisfação de muitos trabalhadores com a infraestrutura da feira móvel é notória, principalmente em relação à eficácia dos direitos sociais (saúde, segurança). Os feirantes relataram que as condições mínimas para a prática de trabalho na feira estão aquém do que deveria ser, pois não há banheiros para os trabalhadores, eles necessitam pagar alguém para manter a segurança e não há uma padronização e revitalização da feira que promova o acesso igualitário dos trabalhadores ao meio ambiente urbano. De modo geral, a feira caracteriza-se por dois principais setores: alimentício e o de vestuário. Além disso, há os que estão à margem do espaço propriamente dito da feira, algo que dificulta o acesso às condições necessárias de desempenho do trabalho digno, como pode ser observado a seguir:

Figura 1: Barraca de roupas e biquínis

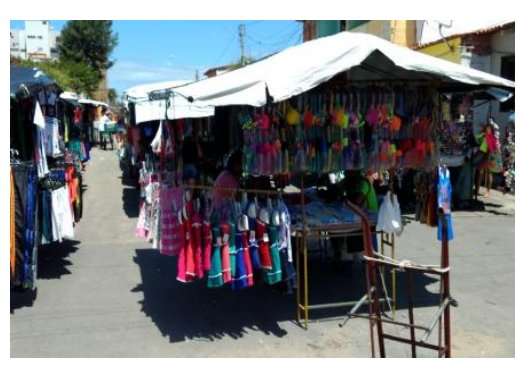

Fonte: Arquivo pessoal do autor (2017).
Figura 2: Barraca de frutas e verduras

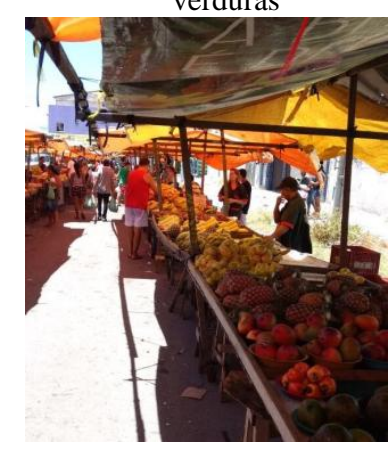

Fonte: Arquivo pessoal do autor (2017).
Figura 3: Comerciantes à margem da feira

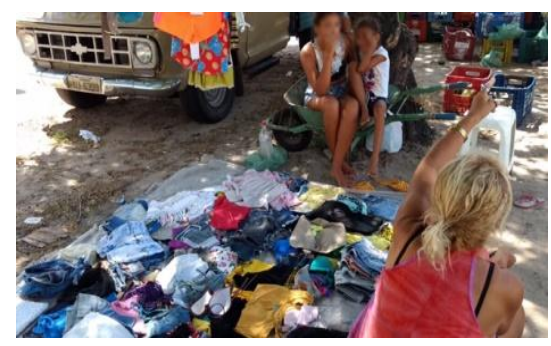

Fonte: Arquivo pessoal do autor (2017).

Verificou-se que há uma quantidade significativa de feirantes interessados em regularizar suas condições trabalhistas. Porém, muitos não possuem informações suficientes acerca das vantagens advindas da formalização e não encontram iniciativas governamentais que promova a disseminação desses conhecimentos. Nesse sentido, há certa efetivação do desenvolvimento econômico, principalmente com a criação da figura jurídica do MEI, a qual acarretou direitos trabalhistas, previdenciários e creditícios aos feirantes. Entretanto, são necessárias medidas que incentivem a formalização dessa prática empreendedora. 


\section{CONCLUSÃO}

Analisar a visão nativa dos feirantes possibilita compreender o nível de eficácia dos direitos fundamentais, previstos na Constituição Federal de 1988, na feira móvel e as suas necessidades perante o Governo e a sociedade em geral. Desse modo, a esfera pública poderá utilizar de meios benéficos para o crescimento desses empreendimentos e efetivar a aplicabilidade desses direitos. Isso pode ser alcançado investindo na infraestrutura do espaço da feira, melhorando a segurança local, transmitindo conhecimentos aos feirantes sobre microempreendimento, dentre outros. Assim, viabiliza-se uma melhoria na vida dos trabalhadores, garantindo-lhes inclusão social e igualdade.

Vale ressaltar que os direitos fundamentais presentes no âmbito trabalhista das feiras móveis não se limitam aos elencados no presente artigo. Portanto, tornam-se necessárias pesquisas que continuem apreendendo conhecimentos relacionados a tais preceitos, sempre em sintonia com os princípios da dignidade da pessoa humana e valorização social do trabalho, como pressupostos para a garantia do trabalho digno nesse espaço urbano.

\section{REFERÊNCIAS}

BARROSO, L. R. O direito constitucional e a efetividade de suas normas - limites e possibilidades da Constituição brasileira. $7^{\text {a }}$ Ed. Rio de Janeiro: Renovar, 2003.

BOBBIO, N. A era dos direitos. 4. reimp. Tradução Carlos Nelson Coutinho. Rio de Janeiro: Campus, 1992.

BONAVIDES, P. Curso de direito constitucional. 15ª Ed. Malheiros, 2004.

BRASIL. Constituição (1988). Constituição da República Federativa do Brasil. Brasília, DF: Senado, 1988.

BRASILEIRO, C.; CAVALCANTE, L. C. Relações de trabalho e cultura da informalidade nas feiras móveis. Revista Extensão em Ação, Fortaleza, v.3, n.12, Out./Dez. 2016.

CACCIAMALI, M. C. Globalização e processo de informalidade. Revista Economia e Sociedade, Campinas, (14): 153-174, jun. 2000. 
CARVAlho, J. M. de. Cidadania do Brasil: o longo caminho. $11^{\text {a }}$ Ed. Rio de Janeiro. Civilização Brasileira, 2008.

CAVALCANTE, L. C.O princípio constitucional da dignidade da pessoa humana como fundamento da produção da existência em todas as suas formas. Dissertação Mestrado em Direito Constitucional. Unifor - 2007.

GEERTZ, C. Uma descrição densa: por uma teoria interpretativa da cultura. Rio de Janeiro: LTC, 1989, p. 13-41.

GIDDENS, A. Sociologia. 4. ed. Porto Alegre: Artmed, 2005.

GIL, A. C. Métodos e técnicas de pesquisa social. 6. ed. São Paulo: Atlas, 2008.

LENZA, P. Direito Constitucional Esquematizado - 16 ${ }^{\text {a }}$ ED. 2012 - Saraiva.

MAFRA, P. D. Camelôs cariocas. In: VELHO, G. (Org.) Cultura, política e conflito. Rio de Janeiro: Jorge Zahar, 2007.

MALINOWSKI, B. (1998 [1922]). Argonautas do Pacífico Ocidental. São Paulo: Abril Cultural, 1922(Os Pensadores).

MARTINS, J. R. Introdução à Sociologia do Trabalho. Curitiba. InterSaberes, 2017.

ORGANIZAÇÃO INTERNACIONAL DO TRABALHO - OIT. Employment, incomes and equality: a strategic for increasing productive employment in Kenya. Geneva: ILO, 1972.

PEIRANO, M. Horizontes antropológicos. Porto Alegre, ano 20, p.377-391, jul./dez. 2014.

SERVIÇO BRASILEIRO DE APOIO ÀS MICRO E PEQUENAS EMPRESAS (SEBRAE). 5 anos: microempreendedor individual - MEI: um fenômeno de inclusão produtiva. Brasília, 2015.

SARLET , I. Dignidade da pessoa humana e Direitos fundamentais na Constituição Federal de 1988. Porto Alegre. Livraria do Advogado Editora, 2007.

SILVA, J. A. da. Curso de Direito Constitucional Positivo. $37^{a}$ Ed. Malheiros. 2014.

SINGER, Paul. Globalização e Desemprego: Diagnóstico e alternativas. São Paulo: Editora Contexto. 2012. 